\title{
UN VIAJE DE CANTEROS SAJONES DE NAUMBURGO A BURGOS
}

\section{A JOURNEY OF SAXONS MASTERS MASONS FROM NAUMBURG TO BURGOS}

\author{
Rafael Cómez Ramos \\ Universidad de Sevilla. España \\ ORCID: 0000-0002-6595-9218 \\ rcomez@us.es
}

\begin{abstract}
Este artículo trata sobre la posible transferencia del taller del llamado maestro de Naumburgo desde Naumburgo y Meissen hasta Burgos hacia 1260 con objeto de realizar las esculturas de las torres y el claustro alto bajo los auspicios de Alfonso X el Sabio dentro de la segunda fase de obras de la catedral de Burgos.

Palabras claves: escultura gótica; escultura conmemorativa; maestro de Naumburgo; catedral de Burgos; Alfonso X el Sabio.
\end{abstract}

This paper deals with the possible transfer of the workshop of the so-called Naumburg Master from Naumburg and Meissen to Burgos around 1260 in order to make the sculptures erected in the towers and the high cloister under the auspices of Alphonse $\mathrm{X}$ the Wise during the second phase of Burgos Cathedral construction.

Keywords: Gothic sculpture; commemorative sculpture; Naumburg Master; Cathedral of Burgos; Alphonse X the Wise.

Plato amicus, sed magis amica veritas

El objeto de este artículo es investigar si una logia de canteros alemanes procedente de las catedrales de Naumburgo y Meissen pudo viajar hasta Castilla en la segunda mitad del siglo XIII para intervenir en la última fase de obras del taller de la catedral de Burgos con motivo de la erección de las estatuas conmemorativas de sus fundadores, Fernando III y Beatriz de Suabia, por su hijo Alfonso $\mathrm{X}$ el Sabio, con motivo de los intercambios diplomáticos y culturales habidos en razón de sus aspiraciones a la corona del Sacro Imperio Romano Germánico por ser legítimo heredero de Beatriz de Hohenstaufen. 
En este sentido, aunque el modelo tradicional se explica en función de la expansión radial de los talleres franceses de la catedral de Reims, donde existen raíces artísticas comunes para todo Occidente, resulta de la mayor importancia averiguar hasta qué punto no pudo intervenir también en la catedral de Burgos un grupo de canteros alemanes especializados en escultura profana, dadas las relaciones políticas entre Castilla y Sajonia, puesto que los únicos ejemplos de estatuas profanas individualizadas, como vemos en el claustro de la catedral de Burgos, no existen en las catedrales francesas sino en las catedrales alemanas de Naumburgo y Meissen. Por lo tanto, nuestra labor ha consistido en estudiar "in situ" dichas catedrales para contrastar sus esculturas con las de la catedral de Burgos ${ }^{1}$, dadas las relaciones políticas entre ambos países en la segunda mitad del siglo XIII.

Conocida es la problemática de un ámbito en el que al no existir documentos escritos, contratos o firmas para determinar una cronología, el análisis estilístico se convierte en el único criterio objetivo de datación o atribución de la escultura medieval. Mucho mayor aún en el caso en que pretendamos establecer hipótesis acerca de relaciones artísticas entre países lejanos por más que nos apoyemos en el análisis arquitectónico para la escultura monumental o nos ayuden las relaciones políticas pues, ciertamente, el análisis estilístico no consiste en una ciencia exacta que resuelva fácilmente el problema. Tal el caso del llamado maestro de Naumburgo y su taller itinerante por Europa que ahora se hace llegar hasta el corazón de Castilla.

\section{I}

Resulta evidente, y es algo en lo que todos los historiadores del arte están de acuerdo, que de los talleres de Reims irradió en toda su plenitud hacia toda Europa la fuerza de su creativo estilo, constatado, entre otros lugares, primero en el Westlettner (leccionario o ambón) de la catedral de Maguncia, donde hubo un taller coordinado por el denominado "maestro de Naumburgo"2 - cuyo estilo es tan

${ }^{1}$ Este trabajo de investigación se enmarca dentro de la Red Nacional de Excelencia "Ars Mediaevalis" (HAR2015-71667-RDT). El autor quiere agradecer al profesor Henrik Karge de la Technische Universität de Dresde su invitación y sus atenciones durante el mes de junio de 2017, en que pudimos hacer uso de la gran biblioteca estatal y universitaria sajona (SLUB) además de conocer las catedrales de Naumburgo, Meissen y Magdeburgo.

2 WILLIAMSON, Paul: Gothic Sculpture, 1140-1300. New Haven y Londres, 1995, p. 177; SCHUBERT, Ernst: Der Naumburger Dom. Berlín, 1968, pp. 30-32; BRUSH, K.: "The Naumburg Master: a chapter in the development of medieval art history", Gazette de Beaux-Arts, CXXII, 1993, pp. 109-122; SAUERLÄNDER, Willibald: "Die Naumburger Stifterfiguren. Rückblick und Fragen", en Cathedrals and Sculpture. T. II. Londres, 2000, pp. 593-711; KROHM, Harmuth y KUNDE, Holger (eds.): Der Naumburger Meister. Bildauer und Architekt im Europa der Kathedralen. 2 vols. Petersberg, 2011; y DONATH, 
expresivo y elocuente que no necesita mayor documentación-, habiéndose convertido en un artista mítico para los historiadores del arte de los siglos XIX y XX por expresar lo más genuino del espíritu alemán medieval, tanto que podemos contemplar sus huellas tanto en Maguncia como en las catedrales de Naumburgo y Meissen.

Probablemente, en el primer lustro de la segunda mitad del siglo XIII, es decir, hacia 1250, bajo el patrocinio del obispo Dietrich II, estarían ya terminadas las esculturas de los primi fundatores -una docena de estatuas distribuidas a lo ancho del muro- en el coro occidental de la catedral de Naumburgo, donde destacan las estatuas del margrave Ekkehard II y su esposa Uta (Figura 1), obra que habría realizado un maestro formado en el taller de Reims, activo en la catedral de Bamberg en la década de 1230, de quien no sabemos si sería solo escultor o también arquitecto que habría dirigido un taller que no debió ser grande, constituido tal vez por dos expertos maestros y media docena de aprendices y canteros que habrían podido concluir el trabajo en un término de cinco años ${ }^{3}$. Con posterioridad, el taller, quizá más reducido, viajaría hasta Meissen, donde su obispo habría decidido enriquecer y emular el coro de Naumburgo ${ }^{4}$ encargando al mismo enigmático maestro las esculturas de San Juan Evangelista y San Donato del muro meridional y las del emperador Otón I y su esposa Adelheid del muro septentrional, santos patronos y fundadores, respectivamente, de la catedral de Meissen. Así pues, en torno a 1260, cuando fueran realizadas estas esculturas, habían transcurrido ya más de veinte años desde que se conociera el gótico francés en Bamberg y Maguncia (Figura 2).

Sin embargo, según Henrik Karge, experto conocedor de la arquitectura gótica en España, resulta demasiado simple la tradicional explicación del desarrollo de la escultura gótica europea derivada de los talleres de las catedrales francesas, singularmente, los de la catedral de Reims. Aun cuando existen evidentes relaciones artísticas entre el taller que realizara las esculturas del claustro y las torres de la catedral de Burgos en la década de 1260 con el taller de Reims, observa paralelos más estrechos con las esculturas de los fundadores de las catedrales de

Günter y RICHTER, Frank: Gärten aus Stein. Die Pflanzenwelt des Naumburger Meisters. Petersberg, 2015.

${ }^{3}$ WILLIAMSON, Paul: Gothic Sculpture, op. cit., pp. 180 y 184.

4 Ibidem, pp. 184-186; SCHUBERT, Ernst: Der Dom zu Naumburg: Architektur und Bildwerke. Berlín, 1990, pp. 319-322; LEHMANN, Ernst y SCHUBERT, Ernst: Der Meissner Dom. Beiträge zur Baugeschichte und Baugestalt bis zum Ende des 13. Jahrhunderts. Berlín, 1968; y KUNDE, Holger: "Mainz-Naumburg-Meissen. Der Naumburger Meister und seine Auftraggeber", en KROHM, Harmuth y KUNDE, Holger: Der Naumburger Meister, op. cit., t. I, pp. 566-581. 
Naumburgo y Meissen, ejecutadas por el llamado maestro de Naumburgo y su taller ${ }^{5}$. Habida cuenta la similitud entre las estatuas de Otón I y Adelheid en el coro de Meissen (Figura 3) con las de Fernando III el Santo y Beatriz de Suabia del claustro de Burgos (Figura 4), aquellas escultura alemanas habrían servido de modelo para las castellanas, lo cual supondría un taller de escultores alemanes en la catedral de Burgos, dadas las relaciones políticas de ambas monarquías por aquellos años. Explicaría la existencia de dicho taller la presencia de ciertos detalles escultóricos de las esculturas burgalesas relacionables con el círculo artístico de Magdeburgo, hallándose el eslabón perdido de esta cadena en unas esculturas del Santo Sepulcro de la catedral de Constanza, realizadas hacia 1260 por encargo del obispo Eberhard II, quien viajó a Burgos en 1257.

Por otra parte, Willibald Sauerländer, máximo conocedor de la escultura gótica, afirmaba que no existe ningún lugar de Europa, antes de 1250, donde la escultura de las portadas monumentales francesas haya sido imitada más fielmente que en la catedral de Burgos ${ }^{6}$. Por el contrario, en la Alemania de los Hohenstaufen, el contacto con las catedrales occidentales se efectúa de muy diferente manera. Mientras que en España se adopta la portada francesa y, a partir de 1240, recibe las nuevas formas del gótico radiante francés, en Alemania pesan demasiado las tradiciones locales que se oponen a la influencia occidental de modo que las grandes esculturas se encuentran dentro pero no en las fachadas de las catedrales ${ }^{7}$. No cabe la menor duda de que un taller conocedor a la perfección de la escultura de Reims trabajó en la catedral de Bamberg hacia 1220, como revela, ciertamente, el grupo de la Visitación de María a su prima Isabel. En la catedral de Maguncia, el sepulcro del arzobispo Siegfried de Epstein, podría haber sido realizado por escultores de Bamberg, que representa el primer hito de la escultura gótica francesa en tierras germánicas pues ningún otro antecedente podemos hallar, por otro lado, para las esculturas de la catedral de Magdeburgo ${ }^{8}$. El taller de Maguncia, famoso por haber intervenido en el impresionante Westlettner del que se conservan notables fragmentos, sería el que llegaría hasta Naumburgo para intervenir en la construcción del coro occidental, cuyos vitrales y esculturas constituyen una admirable unidad espacial sin precedentes en el gótico francés a no ser que nos refiriéramos a la Sainte Chapelle de San Luis.

${ }^{5}$ KARGE, Henrik: "From Naumburg to Burgos. European Sculpture and Dynastic Politics in the Thirteenth Century", Hispanic Research Journal, vol. 13, 5, 2012, p. 434.

${ }^{6}$ SAUERLÄNDER, Willibald: La Sculpture Médiévale. París, s. a., p. 111.

${ }^{7}$ Ibidem, p. 112.

8 Ibid., p. 121; y WILLIAMSON, Paul: Gothic Sculpture, op. cit., p. 184. 
La hipótesis del profesor Henrik Karge arranca de la ponencia presentada en el Coloquio de Naumburgo de 2011 y su contribución al catálogo de la exposición celebrada en el mismo lugar ${ }^{9}$, a las que se han añadido recientes publicaciones en las que abunda en sus argumentos ${ }^{10}$. Su objetivo, partiendo de la tesis de Regine $\mathrm{Abegg}^{11}$, es considerar la escultura monumental del famoso taller de Naumburgo y Meissen en una perspectiva europea que incluya también a la catedral de Burgos en un sentido que se aparte de cualquier interpretación nacionalista alemana, pues admite que los modelos del estilo de Naumburgo se encuentran en la escultura de Reims y Noyon, y reconociendo sus raíces francesas, plantearse la cuestión de otros paralelos europeos que halla en la segunda fase de obras de la catedral de Burgos entre 1260 y $1270^{12}$. Se centra en las esculturas de la galería de reyes de la fachada norte y en las de los jóvenes personajes idealizados de las dos torres de la fachada occidental, así como en todo el programa escultórico de la panda norte del claustro, sin paralelo en la Europa del siglo XIII.

Por otra parte, pone de relieve la similitud de actitudes de la pareja de Fernando III y Beatriz de Suabia con la de Otón I y Adelheid del coro de la catedral de Meissen (Figura 5), lo cual indica cierta relación artística entre Naumburgo, Meissen y Burgos, aunque las raíces comunes procedan de Reims, insistiendo no solo en los detalles sino también en la expresividad. Esta insistencia en la analogía de los detalles incide en el gesto de la mano que sostiene la presilla de la capa, actitud que parece una moda de la época con objeto de sostener el manto, los cuales detalles considera como una relación histórica entre los dos distantes talleres por encima de las características generales del estilo de esa época ${ }^{13}$ cuando, ciertamente, consiste en una imagen muy frecuente desde Saint-Denis a Bamberg o

${ }^{9}$ KARGE, Henrik: "Meissen-Constance-Burgos. European Sculpture and Dynastic Politics in the Thirteenth Century", en Der Naumburger Meister. Forschungen u. Beiträge zum intern. wissensch. Kolloquium in Naumburg von 4 bis 8 Oktober 2011. Vol. 3. 2012, pp. 242-252; y KARGE, Henrik: "Naumburg-Meissen-Burgos. Memorialskulpturen in europäischer Perspektive", en KROHM, Harmuth y KUNDE, Holger (ed.): Der Naumburger Meister, op. cit., t. II, pp. 1452-1463.

${ }^{10}$ KARGE, Henrik: "From Naumburg to Burgos...", op. cit., pp. 434-448; y KARGE, Henrik: "Les programmes sculpturaux des cathédrales de Reims et Burgos et leurs références royales", en DEMOUY, Patrick: La Cathédrale de Reims. París, 2017, pp. 287-310

${ }_{11}$ ABEGG, Regine: Königs und Bischofsmonumente.Die Skulpturen des 13 Jahrhunderts im Kreuzgang der Kathedrale von Burgos. Zurich, 1999.

${ }^{12}$ KARGE, Henrik: "Naumburg-Meissen-Burgos...", op. cit., pp. 1452-1453.

13 Ibidem, p. 1459; SAUERLÄNDER, Willibald, "Die Namburger Stifterfiguren...", op. cit., pp. 593-711. Sobre las capas de cuerda de la época véase MENÉNDEZ PIDAL, Gonzalo: La España del siglo XIII leída en imágenes. Madrid, 1986, pp. 70-72. 
León en su Locus Appellationis, por lo que no deberíamos detenernos tanto en constatar influencias sino más bien en comprobar las diferencias dentro de "la metamorfosis castellana de un lenguaje europeo común", como aconseja Sauerländer ${ }^{14}$. En otro sentido, tras el estudio taxonómico de pliegues y manos, la cuestión palpitante consiste en saber cómo aconteció la transferencia de estos motivos y de qué manera ocurrió tan curiosa recepción del maestro de Naumburgo y su taller en el ya muy activo taller de Burgos.

Siguiendo con sus publicaciones, destaca la calidad de las series de esculturas conmemorativas de los primi fundatores de Naumburgo y el programa escultórico real de la segunda fase de Burgos, promovida por Alfonso X el Sabio, sin parangón en el gótico europeo de la segunda mitad del siglo XIII. Esta segunda fase de obras en la catedral de Burgos viene a coincidir con la década de preocupaciones alfonsíes por la consecución de la corona del Sacro Imperio Romano Germánico, al que tenía derecho por línea materna al ser hijo de Beatriz de Suabia, pues había sido proclamado emperador en 1256 por las ciudades italianas, aunque con posterioridad sería apoyado también al año siguiente por las ciudades alemanas en tal manera que en el intercambio diplomático de legaciones germanas y castellanas cabría la posibilidad de cierta migración artística de la que formara parte el famoso taller de Naumburgo ${ }^{15}$.

Ahora bien, admitida esa posible migración artística es mucho más discutible que ciertos detalles del vestido del grupo de jóvenes reyes del claustro de Burgos se remitan a modelos alemanes del círculo de Magdeburgo y, más concretamente, con el jinete de Magdeburgo, obra de diferente sentido y ubicación profana, aunque más extraordinario nos parece ver relaciones tipológicas entre las esculturas de Naumburgo y las de las torres de la catedral de Burgos, por ejemplo, en el brazo derecho bajo el manto de Uta con una figura del tercer nivel de la torre sur de la fachada occidental de Burgos, cuyo cuerpo se muestra completamente cubierto por el manto en distinta $\operatorname{pose}^{16}$. Más acertada sería la relación de la pareja de Fernando III de Castilla y Beatriz de Suabia del claustro de Burgos con la de Otón I y Adelheid del muro norte del coro de la catedral de Meissen, ya que se trata en ambos casos de dos parejas reales en amorosa contemplación, si bien consideramos muy remota la posibilidad de conexión del taller del maestro de Naumburgo con los maestros del claustro de Burgos.

${ }^{14}$ SAUERLÄNDER, Willibald: "La escultura leonesa a la luz de los grandes talleres europeos”, en YARZA LUACES, Joaquín; HERRÁEZ ORTEGA, M. ${ }^{a}$ Victoria y BOTO VARELA, Gerardo (eds.): Congreso Internacional "La Catedral de León en la Edad Media”. Actas. León, 2004, pp. 201-202.

15 KARGE, Henrik, "From Naumburg to Burgos...", op. cit., pp. 438 y 439.

${ }^{16}$ Ibidem, p. 440. Sobre las esculturas de las torres y del claustro de la catedral de Burgos véase ABEGG, Regine: Königs und Bischofsmonumente, op. cit., pp. 110-114 y 117-130. 
Sin embargo, menos consistente resulta la comparación de la Virgen de la Anunciación del claustro de Burgos (Figura 6) con la Virgen de la Anunciación de la capilla del Santo Sepulcro de la catedral de Constanza, fijándose en la manera de agarrar el extremo del manto con la mano izquierda cuando la pose de ambas figuras es diferente, apoyándose, por otra parte, en que su comitente, el obispo Eberhard II de Constanza, formara parte del cortejo que viajó a Burgos en 1257. Y toda la documentación que se pueda aportar, incluido el epistolario sobre su largo viaje hasta Burgos, no prueba que con el obispo de Constanza haya llegado también a Castilla el maestro de Naumburgo con su famosa logia ${ }^{17}$. Esta relación implica olvidar el papel indiscutible del maestro Enrique, procedente de la Champaña, y los artistas franceses que le acompañaran, no solo en el taller de Burgos sino también en el de la nueva catedral de León, cuya obra dirigiría también hasta su muerte ${ }^{18}$. Además, parece olvidar el juicio de un buen conocedor de ambos talleres cuando, poniéndolos uno junto al otro, afirmaba:

"Las esculturas de los donantes en el coro de la catedral de Naumburgo son una respuesta a los modelos de Reims, pero su apariencia maciza y pesada, su oscuro pathos, tienen un carácter propio e independiente. Las formidables figuras de los reyes Fernando III y Beatriz de Suabia del claustro de la catedral de Burgos están probablemente inspiradas en Reims, pero las vestiduras y el gracioso gesto de la encantadora reina se ven en las miniaturas de las Cantigas de Santa María de Alfonso X el Sabio, no encontrándose en ninguna parte al norte de los Pirineos" 19 .

Abundando en los detalles aducidos por Karge, nos parece que el referido al sobaco de Beatriz de Suabia del claustro de Burgos comparado con los del Hipócrates del Santo Sepulcro de Constanza o los reyes que corona en su tumba de la catedral de Maguncia, el arzobispo Siegfried III von Epstein ${ }^{20}$, no son razón suficiente para considerarlos modelos de la escultura castellana en Burgos, para

${ }^{17}$ KARGE, Henrik: "From Naumburg to Burgos...", op. cit., pp. 438 y 440-442.

18 FRANCO MATA, Ángela: "Alfonso X el Sabio y las catedrales de Burgos y León", Norba-Arte, VII, 1986, pp. 71-81; FRANCO MATA, Ángela: Escultura gótica en León y provincia (1230-1530). León, 1998, pp. 321-357; IGLESIAS ROUCO, Lena S.: "La catedral de Burgos", en NAVASCUÉS PALACIO, Pedro y GUTIÉRREZ ROBLEDO, José Luis (eds.): Medievalismo y Neomedievalismo en la arquitectura española: Las Catedrales de Castilla y León I. Actas de los congresos de Septiembre 1992 y 1993. Ávila, 1994, pp. 95116; KARGE, Henrik: La catedral de Burgos y la arquitectura del siglo XIII en Francia y España. Valladolid, 1995, pp. 51, 193-195 y 117-124; y KARGE, Henrik: "La catedral de León...”, op. cit., pp. 142-143.

19 SAUERLÄNDER, Willibald: "La escultura de la sede leonesa a la luz de los grandes talleres europeos”, en YARZA LUACES, Joaquín; HERRÁEZ ORTEGA, Ma Victoria y BOTO VARELA, Gerardo (eds.): Congreso Internacional "La Catedral de León en la Edad Media". Actas, op. cit., p. 179.

${ }^{20}$ KARGE, Henrik: "From Naumburg to Burgos...", op. cit., p. 442. 
poner en conexión puntos tan dispares como Naumburgo, Meissen, Maguncia y Constanza en coincidencia con sus respectivas cronologías. Si observamos este motivo veremos que es frecuente en la escultura de ese momento y aparece, por ejemplo, en el rey de uno de los nichos de la fachada occidental interior de la catedral de Reims ${ }^{21}$. Considerando nula posibilidad que estas semejanzas se deban a dibujos que hubieran llegado a Burgos desde Naumburgo, concluye que la única explicación es que escultores alemanes hayan llegado al taller burgalés para adiestrar a los españoles que ya trabajaban en la catedral, aunque reconoce por las formas duras y geométricas de las esculturas burgalesas que las conexiones artísticas entre la escultura alemana y la española no son tan próximas como las existentes entre las esculturas de Naumburgo y Meissen ${ }^{22}$.

No obstante, llega a concebir que, tras la elección del rey de Castilla como emperador del Sacro Imperio Romano Germánico en 1257, el propio Alfonso $\mathrm{X}$ haya querido emplear a los mejores artistas alemanes, es decir, al maestro de Naumburgo y su taller, "para demostrar su dignidad" en el programa escultórico de la catedral de Burgos en el que se representa al anterior monarca y toda su familia. Finalmente, la explicación de que hasta ahora no se haya tenido en cuenta esta relación del maestro de Naumburgo con el maestro Enrique de Burgos se debe a que veamos a Francia y no Alemania como el más importante centro artístico europeo de donde irradian las influencias artísticas en el siglo XIII ${ }^{23}$. Ahora bien, aunque consideremos otros importantes centros artísticos europeos donde se desarrolla una escultura de excepcional calidad, no podremos nunca dejar de aceptar que fue el nordeste de Francia y, concretamente, los talleres de la catedral de Reims de donde emanaron las más trascendentes influencias para el desarrollo de la escultura gótica europea en el siglo XIII.

Continuando con el desarrollo de su última publicación, volvemos al comentario de las partes altas de las fachadas de la catedral de Burgos y sus torres. Del mismo modo que en la fachada sur estarían representados Jesucristo acompañado por doce ángeles, las doce estatuas de la fachada norte representan a los antepasados de Alfonso X el Sabio, promotor de esta segunda fase de obras. Por otro lado, la fachada occidental nos presenta en las torres una serie de esculturas de jóvenes idealizados que han sido interpretados como "una perpetua procesión real" 24 . La serie escultórica de la galería de la fachada occidental ha estado abierta a muchas interpretaciones: Deknatel quiso ver en las figuras de los ocho reyes a los antepasados de Cristo por analogía con otros de

${ }^{21}$ SAUERLÄNDER, Willibald: Gotische Skulptur, 1140-1270. Munich, 1970, p. 170, lám. 260.

${ }^{22}$ KARGE, Henrik: "From Naumburg to Burgos...”, op. cit., p. 444.

23 Ibidem.

${ }^{24}$ KARGE, Henrik: "Les programmes sculpturaux...”, op. cit., p. 292; y ABEGG, Regine: Königs und Bischofsmonumente, op. cit., pp. 113-114. 
la catedral de Chartres $^{25}$, mientras que Von Hohenzollern las interpreta como la genealogía monárquica de Fernando III, rey de Castilla y de León, partiendo de idénticas galerías de las catedrales de París, Chartres, Amiens y Ruán, que serían sus ilustres antecedentes ${ }^{26}$ (Figura 7). Hace mucho nos aventuramos a ver en el grupo de la torre sur a los siete infantes, hijos de Fernando III el Santo, al tiempo que, sin conocer la tesis anterior de Von Hohenzollern, coincidíamos en ver también en la galería occidental a los ocho reyes de Castilla y León, desde Fernando I a Alfonso IX, padre de Fernando III $^{27}$. No obstante, recientemente, han sido interpretados como los hijos de Fernando III, a saber, observados de izquierda a derecha del espectador: Alfonso que porta una flor de lis, Fadrique, Fernando, Enrique, Felipe, Sancho, Berenguela y el benjamín Manuel, que acaricia un animal de compañía ${ }^{28}$.

Sin embargo, obviamente, el conjunto de escultura conmemorativa más interesante se encuentra en el claustro, singularmente en el muro norte, donde se encuentra la pareja real de Fernando III y Beatriz de Suabia, que se desposaron en la antigua catedral en 1219, lo cual permite plantear la influencia directa de Alfonso $\mathrm{X}$ en el programa artístico catedralicio ya que, como descendiente de los Hohenstaufen por línea materna, tenía derecho a la corona del Sacro Imperio Romano Germánico. Habida cuenta de los modelos de la catedral burgalesa en Bourges y Tours (Figura 8), no conviene olvidar en esta segunda fase de obras bajo el reinado de Alfonso X el influjo ejercido por la arquitectura de las fundaciones reales de París, entre las que la Sainte Chapelle de San Luis desempeña un claro papel, como señala Karge, en el diseño de sus ventanas comparadas con las del piso superior del claustro de Burgos ${ }^{29}$; no obstante, el significado simbólico y ceremonial de la catedral de Reims para la monarquía francesa la convirtieron en "un modèle prédestiné" 30 de los programas escultóricos de la monarquía castellana en la catedral de Burgos.

Aunque está demostrado que existe una estrecha relación entre la escultura de la catedral de Burgos y sus modelos de la catedral de Reims, parece que a partir de 1260, bajo el reinado de Alfonso X el Sabio, los programas escultóricos

${ }^{25}$ DEKNATEL, Frederick B.: "The Thirteenth Century Gothic Sculpture of the Cathedrals of Burgos and Leon", The Art Bulletin, XVII, 1935, p. 284.

${ }^{26}$ HOHENZOLLERN, Johann Georg, Prinz Von: Die Königsgalerie der französischen Kathedrale. Herkunft, Bedeutung, Nachfolge. Munich, 1965, pp. 92 y 95-99.

${ }^{27}$ CÓMEZ RAMOS, Rafael: Las empresas artísticas de Alfonso X el Sabio. Sevilla, 1979, pp. 167 y 169; y FRANCO MATA, Ángela: "Alfonso X el Sabio y las catedrales de Burgos y León”, Norba-Arte, VII, 1987, pp. 71-81,

${ }^{28}$ KINKADE, Richard: "Hermanos ofendidos. Contiendas fraternales en el reinado de Alfonso X", Alcanate. Revista de estudios alfonsíes, XI, 2018-2019, pp. 97-121.

${ }^{29}$ KARGE, Henrik: "Les programmes sculpturaux...”, op. cit., p. 298.

30 Ibidem, p. 300. 
"muestran un carácter estilístico más homogéneo y menos dependiente de los modelos franceses" porque las fuentes más importantes de dicho estilo se encuentra en las catedrales alemanas de Naumburgo y Meissen y sus semejanzas con Burgos van más allá de sus correspondencias tipológicas, aun cuando existan ciertas analogías entre las esculturas de los nichos del reverso de la fachada principal de la catedral de Reims con las de las torres y el claustro burgalés ${ }^{31}$. En este sentido, con objeto de demostrar la relación de los talleres de Meissen y Burgos, se han estudiado las marcas de canteros existentes en el muro norte del claustro de Burgos y, singularmente, las que aparecen en torno a la pareja escultórica de Fernando III y Beatriz de Suabia para concluir que un equipo de canteros procedentes de Meissen y, previamente, de Naumburgo habría viajado hasta Burgos en la década de 1260 para integrarse en los talleres que trabajaban en el claustro y las galerías altas de la catedral ${ }^{32}$.

Ahora bien, si esto es así, sabido es que los signos lapidarios aparecen por toda Europa con unas características similares y tales similitudes gliptográficas en Burgos habría que confrontarlas también con otras partes de la catedral para comprobar asimismo las diferencias al mismo tiempo que se realiza el análisis histórico artístico. En el cuadro de marcas del taller de Naumburgo que presenta Günther Donath, podemos comprobar la variedad y frecuencia de signos de canteros y escultores de esa logia tanto en Naumburgo como en Meissen ${ }^{33}$. Por otro lado, si admitimos las similitudes estilísticas entre las ventanas de la Sainte Chapelle parisina y las ventanas del claustro burgalés ${ }^{34}$, resulta difícil entender que haya acudido también a dicho enclave donde ya dirigía la obra un maestro francés otro maestro alemán, es decir, el famoso maestro de Naumburgo y su taller para intervenir exclusivamente en esa zona. Además, no sabemos cómo podríamos conciliar las analogías de las esculturas de los nichos del reverso de la fachada principal de Reims -mencionadas más arriba- con las de las torres y el claustro de Burgos, realizadas ambas en la década de $1260^{35}$. Según Karge, hay que suponer que los contactos diplomáticos de 1257 habrían preparado el camino para la llegada de los canteros y escultores alemanes, constituyéndose un melting pot en el que los artistas alemanes transmitieron sus conocimientos a los españoles, que ya habían sido entrenados por los franceses, lo cual no excluye que los escultores hayan utilizado dibujos y modelos traídos de su país de origen. Finalmente, hace la distinción entre las esculturas de las galerías de las fachadas y las partes altas del edificio, cuya clara referencia es la catedral de Reims, y las esculturas del claustro, entre las que destaca la pareja real de Fernando III y su esposa

\footnotetext{
31 Ibid., pp. 303 y 305.

32 Ibid., p. 305.

${ }^{33}$ DONATH, Günter y RICHTER, Frank: Gärten aus Stein ..., op. cit., p. 26, fig. 20.

${ }^{34}$ Véase nota 29.

${ }^{35}$ SAUERLÄNDER, Willibald: Gotische Skulptur..., op. cit., p. 160, lám. 260.
} 
Beatriz de Suabia, cuyos modelos serían las estatuas del emperador Otón I y su esposa Adelheid, realizadas en Meissen por el taller de Naumburgo ${ }^{36}$.

\section{III}

No es la primera vez que se relaciona a la pareja de Fernando III y Beatriz de Suabia del claustro de la catedral de Burgos con el maestro de Naumburgo. El gran hispanista Hugo Kehrer ${ }^{37}$ llegó a suponer que un maestro burgalés hubiera entrado en contacto con el naumburgués o incluso hubiera conocido el coro occidental de Naumburgo. Señala la posición de los pies separados -detalle común a las esculturas del taller de Burgos, como se puede comprobar también en las estatuas de las galerías y de las torres-, así como la actitud de ofrecer el anillo a la novia que, sin ofrecerle el dedo, responde con una sonrisa de aprobación. Solo el rey lleva corona, pues la reina porta una toca alta burgalesa "como no se halla otra ni en Alemania ni en Francia"38. Y para apostillar la germanidad de la pareja recurre a una cita de Carl Justi:

"Los rasgos de Fernando tienen las características del tipo germano, como los de la novia alemana, que son todavía más finos de línea. La sangre visigoda se ha conservado pura en la Casa real de León" 39.

En cambio, por otra parte, otro gran hispanista alemán, August Mayer ${ }^{40}$, al estudiar las esculturas de las torres y el claustro de la catedral de Burgos, habla de un maestro francés que trabajaría hacia 1275 sin mencionar a ningún maestro

${ }^{36}$ KARGE, Henrik: "Les programmes sculpturaux...”, op. cit., p. 309 y nota 47.

${ }^{37}$ El historiador del arte Hugo Kehrer fue uno de los mejores expertos en la pintura de El Greco. Hasta 1945 fue profesor de la Universidad de Munich. Perteneció al NSDAP y en 1939 dedicó su obra Greco als Gestalt des Manierismus al Generalísimo Franco.

${ }^{38}$ KEHRER, Hugo: Alemania en España. Influjos y contactos a través de los siglos (trad. de Deutschland in Spanien. Beziehung, Einfluss und Abhängigkeit, Munich, 1953). Madrid, 1966, p. 29. Sobre los tocados femeninos véase MENÉNDEZ PIDAL, Gonzalo: La España del siglo XIII..., op. cit., pp. 86-93.

39 JUSTI, Carl: Miscellaneen aus drei Jahrhunderten spanischen Kunstlebens. T. I. Berlín, 1908, p. 34. Apud KEHRER, Hugo: Alemania en España, op. cit., p. 29, nota 2.

${ }^{40}$ August L. Mayer fue discípulo de Heinrich Wölfflin y el mejor conocedor de la Historia del Arte en España en la primera mitad del siglo XX. Experto en pintura española del Siglo de Oro, se convirtió en el gran tratadista de la pintura española, ocupando el cargo de conservador jefe de la Alte Pinakothek de Munich hasta que una campaña de desprestigio orquestada por profesores universitarios acabó con su vida el año 1944 en Auschwitz -no en Niza como afirmara KEHRER, Hugo: Alemania en España, op. cit., p. 131-. Véase POSADA KUBISSA, Teresa: August L. Mayer y la pintura española. Ribera, Goya, El Greco, Velázquez, Madrid, 2010. 
alemán ${ }^{41}$. Contrasta esta percepción con la de los modernos historiadores que persisten en el naumburgischen Aspekt de las esculturas de la catedral de Burgos, continuando la saga de sus antecesores ${ }^{42}$.

En otro sentido, resulta llamativo en qué manera, al referirse a la conexión Naumburgo-Meissen-Burgos, ni Henrik Karge ni Regine Abegg hacen mención de Willibald Sauerländer, máximo experto de la escultura gótica europea, conocedor, por supuesto, tanto de la escultura alemana como de la escultura española, ya que dedicó sendos estudios al coro de la catedral de Naumburgo ${ }^{43}$ como a los talleres de la catedral de León ${ }^{44}$. Sauerländer defendió siempre el indiscutible influjo francés incluso en las creaciones más específicas del "genio germánico" como las esculturas del transepto sur de la catedral de Estrasburgo, rechazando cualquier ditirambo nacionalista respecto al indudable carácter alemán de las esculturas de Naumburgo y Bamberg ${ }^{45}$. Además, era reacio a describir el carácter nacional de las doce esculturas del coro de Naumburgo por no caer en el círculo vicioso de afirmar que dichas estatuas son alemanas porque son expresivas o que "son expresivas porque son alemanas", cayendo en la falacia psicológica de la expresividad, pues el análisis estilístico tampoco ofrece una salida cabal al dilema ${ }^{46}$.

En esta tesitura el exhaustivo análisis de detalles y aspectos expresivos aducidos por Henrik Karge nos conduce a un dilema aún mayor pues, ciertamente, "fundadores" de la catedral fueron Fernando III y Beatriz de Suabia como lo fueron Ekkehard y Uta y Otón II y Adelheid en sus respectivos lugares. Ahora bien,

${ }^{41}$ MAYER, August L.: El estilo gótico en España (trad. de Gotik in Spanien. Leipzig, 1928). $3^{\text {a }}$ ed., Madrid, 1960, pp. 37-47.

42 ABEGG, Regine: “...Den Stiftern zu Naumburg vergleichbar...”, en KROHM, Harmuth y KUNDE, Holger (eds.): Der Naumburger Meister, op. cit., pp. 1463-1465.

${ }^{43}$ SAUERLÄNDER, Willibald: "Die Naumburger Stifterfiguren...", op. cit., t. II, pp. 593-711; y SAUERLÄNDER, Willibald: "Stiftergedenken und Stifterfiguren in Naumburg", en Cathedrals and Sculpture, op. cit., t. II, pp. 712-727.

${ }^{44}$ SAUERLÄNDER, Willibald: "La escultura de la sede leonesa...", op. cit., pp. 177 202.

${ }^{45}$ SAUERLÄNDER, Willibald: Cathedrals and Sculpture, op. cit., t. I, Introducción, p. III. Véase SAUERLÄNDER, Willibald: Cathedrals and Sculpture, op. cit., t. II, "Reims und Bamberg. Zu Art und Umfang der Übernahmen", pp. 557-592. Con el mismo sentido crítico véase SAUERLÄNDER, Willibald: "Style or Transition? The fallacies of classification discussed in the light of German architecture 1190-1260", Architectural History, 30, 1987, pp. 1-13.

46 SAUERLÄNDER, Willibald: Cathedrals and Sculpture, op. cit., t. I, Introducción, pp. III-IV. En este sentido véase la fotografía de un carro en el desfile de la celebración de los 2000 Años de Cultura Alemana (Munich, 10 de julio de 1938) en el que se ha reproducido el coro de Naumburgo con las estatuas de los primi fundatores. SAUERLÄNDER, Willibald: Cathedrals and Sculpture, op. cit., t. II, "Die Namburger Stifterfiguren”, p. 648, fig. 1. 
independientemente de las relaciones políticas y diplomáticas que existieron en aquella coyuntura entre ambos países ${ }^{47}$, en el análisis comparativo deberíamos observar nos solo las semejanzas sino también las diferencias, considerando distintos tipos de analogías, a saber: a) El motivo característico de los pies separados en ángulo que vemos en las esculturas de las torres y el claustro de Burgos, rasgo típico del taller burgalés, no lo observamos en las esculturas de Naumburgo y Meissen; b) Las esculturas de Fernando III y Beatriz de Suabia sobre consolas están entregadas al muro del claustro de Burgos como las de Otón y Adelheid en el coro de Meissen ${ }^{48}$, pero estas consolas son lisas mientras que las burgalesas son diferentes y recubiertas de decoración vegetal; en Naumburgo, las estatuas de Ekkehard y Uta se encuentran adosadas y apoyándose en una moldura del correspondiente pilar; y c) La pareja de Fernando III y Beatriz de Suabia, conmemorativa de la boda que tuvo lugar en la antigua catedral románica de Burgos, con el gesto de entregar el anillo nupcial a la novia es muy diferente a la pareja de Otón II y su esposa Adelheid en Meissen, aunque ambas sean de una gran expresividad. La actitud de agarrar la presilla del manto es común en la escultura de la época y no cabe señalarla como característica del maestro de Naumburgo ${ }^{49}$. En Naumburgo y Meissen las esculturas se encuentran en los ábsides de las catedrales, en Burgos están en el claustro. En Burgos, el rey se sitúa a la izquierda del espectador, en cambio, en Meissen está a la derecha. Las sonrisas de las reinas son muy diferentes aunque consistan en el típico rictus derivado de los talleres de Reims.

En una ocasión, al tratar del desarrollo artístico de Castilla en el siglo XIII, pusimos las esculturas de Fernando III y Beatriz de Suabia del claustro de Burgos en parangón con las de Ekkehard y Uta del coro de Naumburgo en cuanto obras maestras de la escultura medieval europea sin establecer relaciones formales o

${ }^{47}$ WOLF, Amin: "El proyecto imperial de Alfonso X", en RODRÍGUEZ LLOPIS, Miguel (coord.): Alfonso X y su época. El siglo del Rey Sabio. Barcelona, 2001, pp. 153173; MEYER, Bruno: Kastilien, die Staufer und das Imperium. Ein Jahrhundert politischer Kontakte im Zeichen des Kaisertums, Husum, 2002, pp. 84-94; y MEYER, Bruno: "Dynastiche Verbindungen zwischen Kastilien und dem Reich zur Zeit der Staufer", en VALDEÓN, Julio; HERBERS, Klaus y RUDOLF, Karl (coords.): España y el Sacro Imperio: procesos de cambios, influencias y acciones recíprocas en la época de la "europeización". Valladolid, 2002, pp. 63-85.

${ }^{48}$ KARGE, Henrik: "Memorialskulpturen in europäischer Perspektive", en KROHM, Harmuth y KUNDE, Holger (eds.): Der Naumburger Meister, op. cit., p. 1460; KARGER, Henrik: "From Naumburg to Burgos...", op. cit., p. 440; y ABEGG, Regine: Königs und Bischofsmonumente, op. cit., pp. 117-118. Vid láms. 58-62.

49 SAUERLÄNDER, Willibald: "La escultura de la sede leonesa...", op. cit., pp. 201-202. 
estilísticas entre ellas ni suponer un viaje de aquel taller hasta Burgos ${ }^{50}$. Por más que llevemos la relación Naumburgo-Meissen-Burgos hasta las raíces de una anterior conexión hispánica con la escultura de la catedral de Bamberg ${ }^{51}$, hallaremos siempre en la base de ese sustrato la fuente de los talleres de Reims. Incluso si pensáramos en una influencia directa de la corte de Alfonso X el $\mathrm{Sabio}^{52} \mathrm{o}$, asimismo, del propio rey en el programa iconográfico de la catedral de Burgos, no resulta fácil imaginar pues, por otra parte, sabemos que Alfonso X no viajó más allá de Montpellier en Francia ${ }^{53}$.

Hoy por hoy, a pesar de todos los estudios dedicados a la personalidad del famoso maestro de Naumburgo, su enigmática figura permanece desconocida como afirmara antaño Ernst Schubert ${ }^{54}$, y aún más problemática si prolongamos su itinerario desde el centro de Europa hasta Burgos pues en otros maestros canteros tenemos los eslabones intermedios de su viaje ${ }^{55}$; sin embargo, en nuestro caso esos hitos no están claros o, en todo caso, son inverosímiles ${ }^{56}$. Por el contrario, parece verosímil que alguien haya visto, encargado o sugerido que las esculturas de Fernando III y Beatriz de Suabia en el claustro de Burgos fueran de forma y manera parecidas a las de Otón II y Adelheid del coro de Meissen pero, claro está, este aspecto es el que queda por demostrar fehacientemente pues hasta ahora nos movemos en el terreno de las hipótesis.

En el noble juego de las facultades del espíritu, la extraordinaria y exhaustiva investigación de Karge, apartándose, ciertamente, de la interpretación nacionalista como aseveraba en su primer estudio sobre la supuesta conexión Naumburgo-Meissen-Burgos ${ }^{57}$, no ha podido evitar sumarse, no obstante, involuntariamente, a una tendencia que no es rara en la historiografía de arte

${ }^{50}$ CÓMEZ RAMOS, Rafael: "Tradición en innovación artísticas en Castilla en el siglo XIII", Alcanate. Revista de Estudios Alfonsíes, III, 2002-2003, p. 145; y CÓMEZ RAMOS, Rafael: "La monarquía castellana y el arte gótico", en RODRÍGUEZ LLOPIS, Miguel (coord.): Alfonso X y su época, op. cit., p. 300.

${ }^{51}$ RICKERT, Claudia: "Die sogennante ältere Bildhauerwerkstatt des Bamberger Doms und ihre spanischen Wurzeln", en HEGENER, Nicole; LICHTE, Claudia y MARTEN, Bettina (eds.): Curiosa Poliphili. Festgabe für Horst Bredekamp zum 60 Geburtstag. Leipzig, 2007, pp. 83-91.

${ }_{52}$ KARGE, Henrik: "Les programmes sculpturaux...", op. cit., p. 294.

${ }^{53}$ GONZÁLEZ JIMÉNEZ, Manuel: Alfonso X el Sabio. Barcelona, 2004, pp. 280-283.

${ }^{54}$ SCHUBERT, Ernst: Der Naumburger Dom. Berlín, 1968, pp. 30-31.

${ }_{55}$ CÓMEZ RAMOS, Rafael: La historia de Villard de Honnecourt: Arquitectura y crítica. Sevilla, 2009, pp. 27-74.

${ }^{56}$ KARGE, Henrik: "From Naumburg to Burgos...”, op. cit., pp. 440-441, figs. 5-7.

${ }^{57}$ KARGE, Henrik: "Memorialskulpturen in europäischer Perspektive", op. cit., p. 1452 . 
alemana $^{58}$ al considerar unos modelos que representan lo más característico del espíritu alemán cuando, por otra parte, reconoce que ningún otro país europeo ha aceptado con más vehemencia una recepción de sistemas arquitectónicos y decorativos franceses como España ${ }^{59}$.

Fecha de recepción: 30 de octubre de 2018

Fecha de aceptación: 5 de febrero de 2019

${ }^{58}$ CÓMEZ RAMOS, Rafael: "La iglesia de Santa Isabel de Marburgo del Lahn. Un ejemplo del nacionalismo en la Historia del arte", Laboratorio de Arte, 16, 2003, pp. 13-47.

${ }_{59}$ KARGE, Henrik: "De Santiago de Compostela a León: modelos de innovación en la arquitectura medieval española. Un intento historiográfico más allá de los conceptos de estilo", Anales de Historia del Arte, vol. extra, 2009, p. 194. 


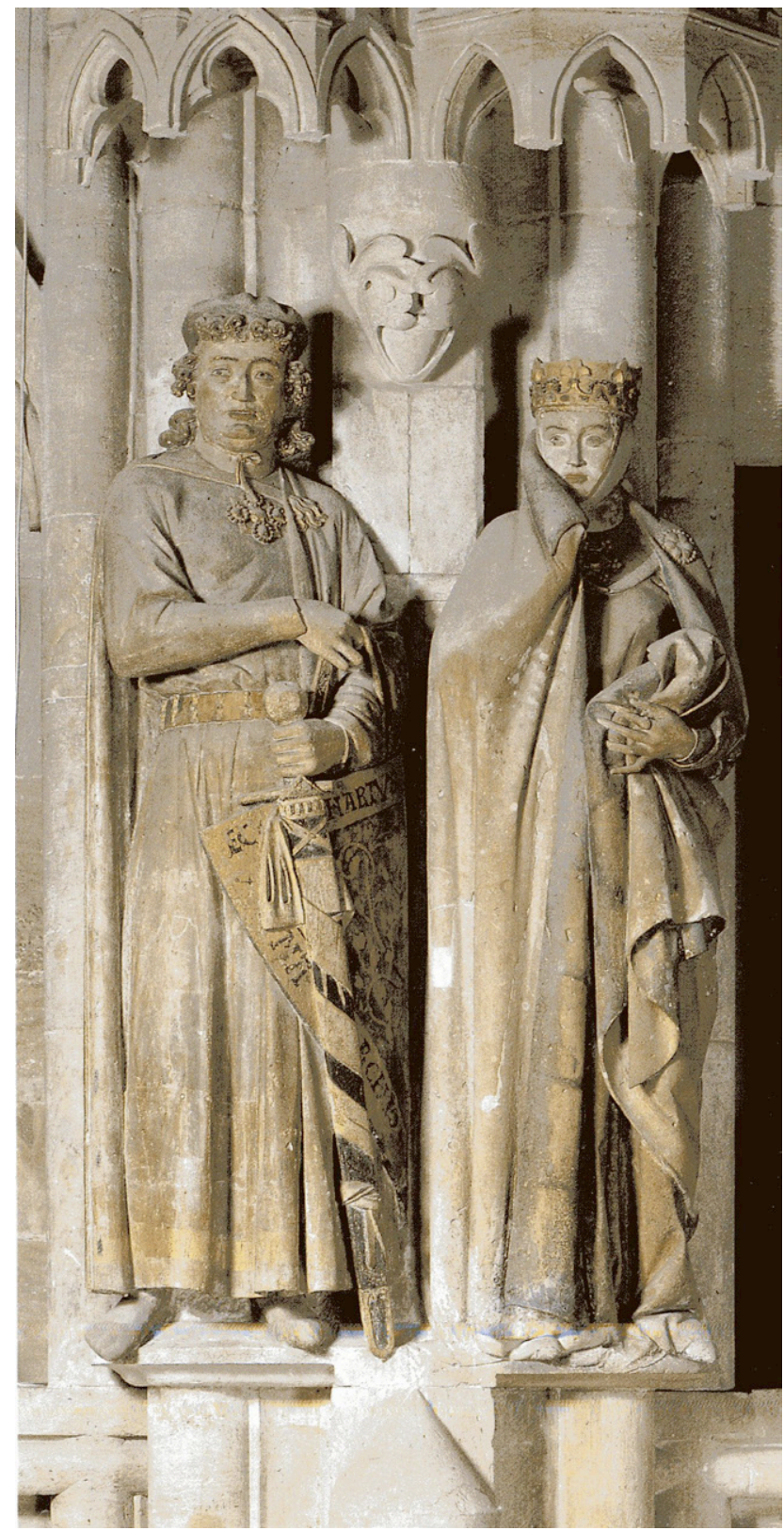

Figura 1. Ekkehard y Uta, catedral de Naumburgo. Foto: Rafael Cómez Ramos. 


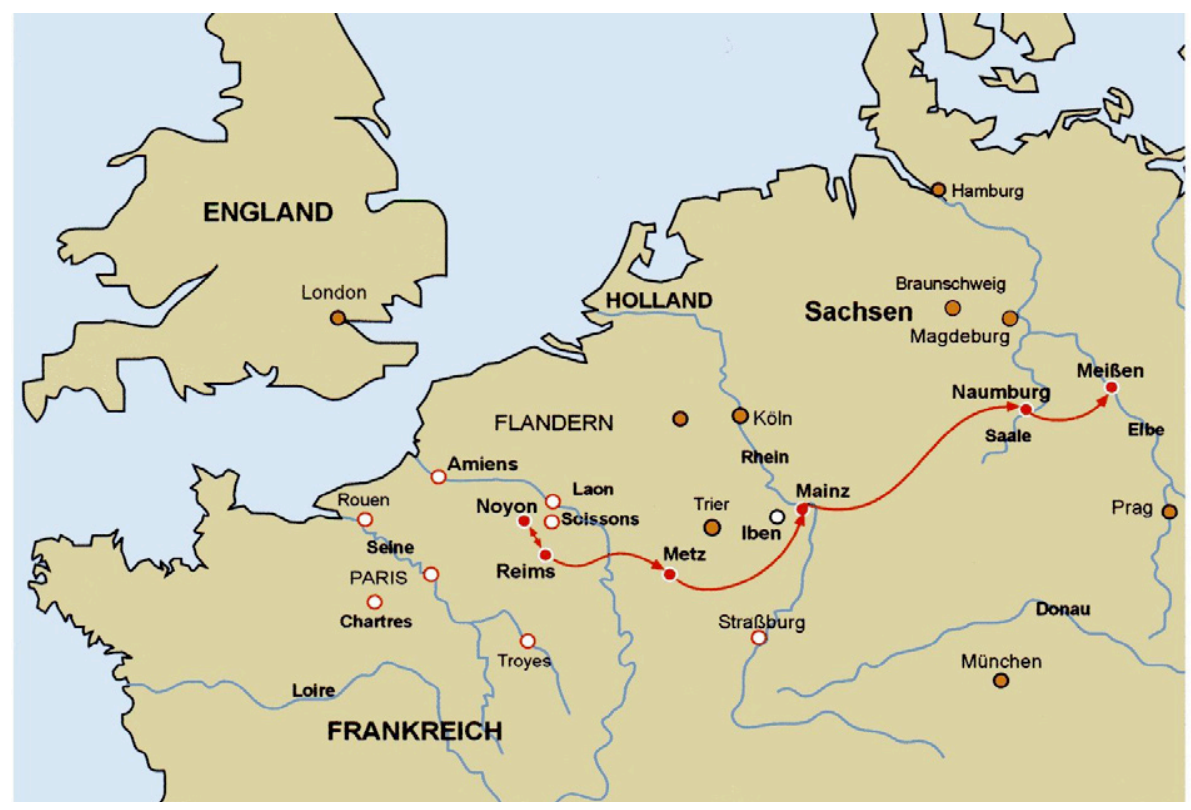

Figura 2. Itinerario del maestro de Naumburgo. DONATH, Günter u. RICHTER, Frank: Gärten aus Stein. Die Pflanzenwelt des Naumburger Meisters. Petersberg, 2015, p. 28, fig. 22.

Figura 3. Otón I y Adelheid, catedral de Meissen. Foto: Rafael Cómez Ramos.

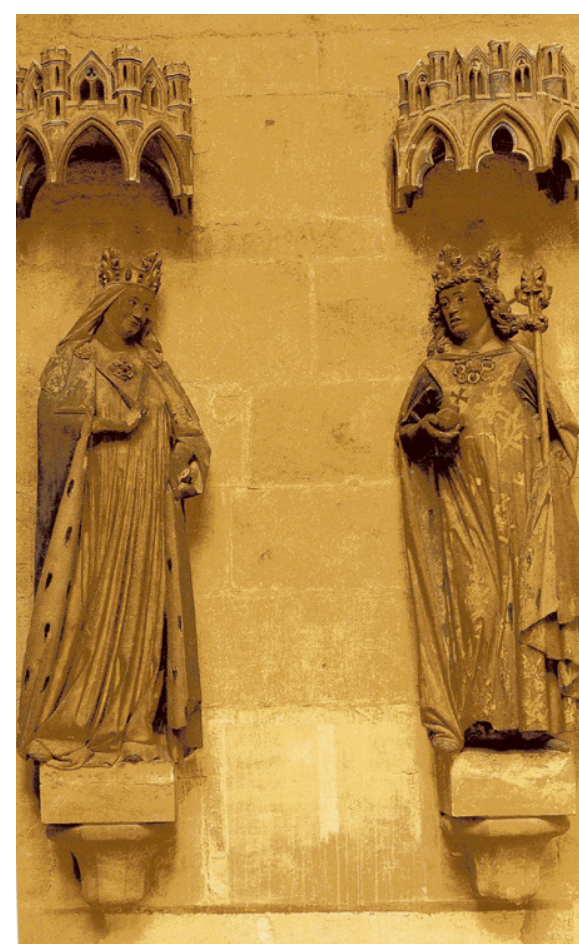




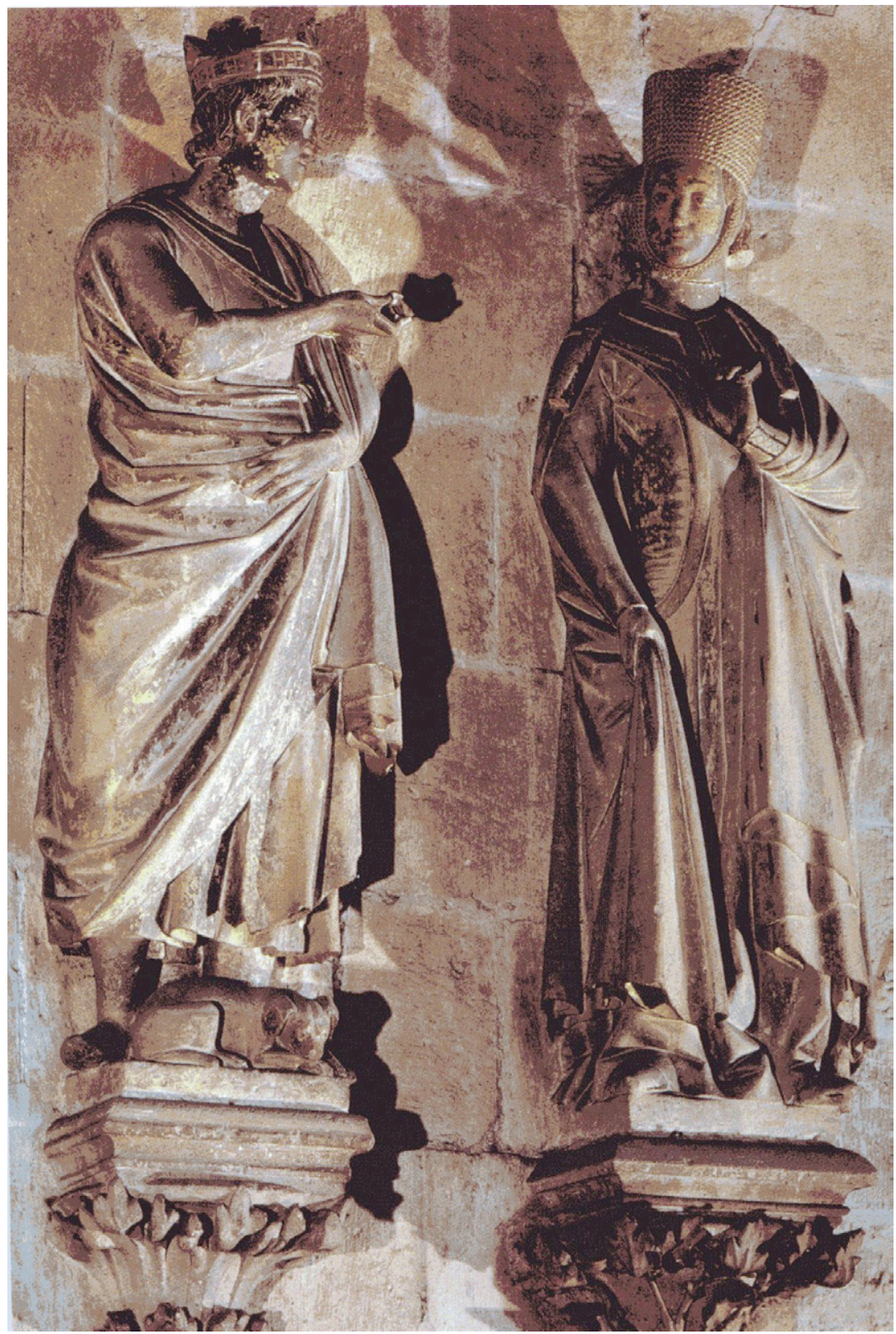

Figura 4. Fernando III el Santo y Beatriz de Suabia, claustro alto de la catedral de Burgos. Foto: Rafael Cómez Ramos. 


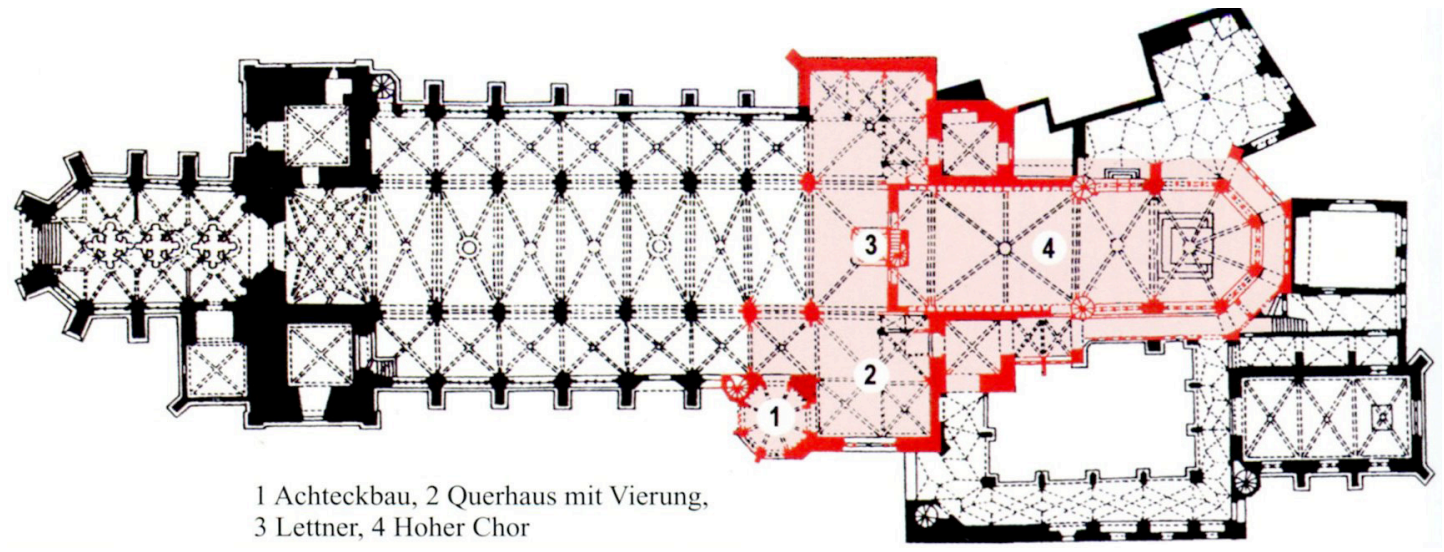

Figura 5. Planta, catedral de Meissen. DONATH, Günter u. RICHTER, Frank: Gärten aus Stein. Die Pflanzenwelt des Naumburger Meisters. Petersberg, 2015, p. 52, fig. 66.

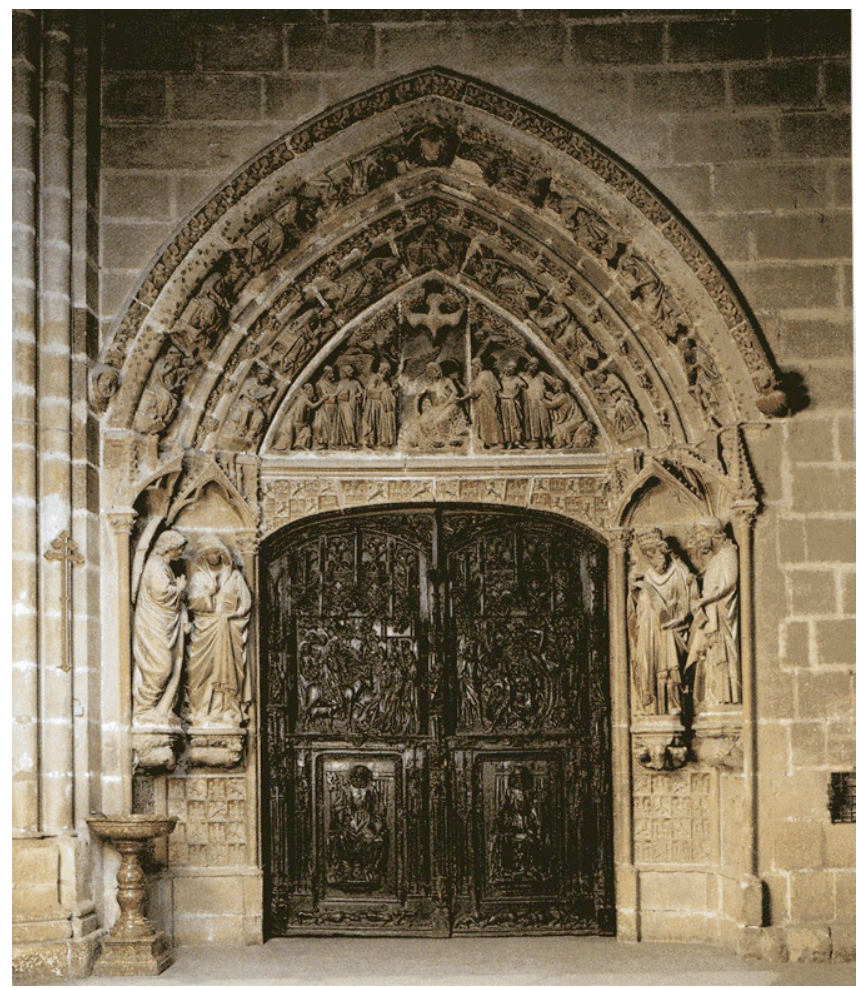

Figura 6. Portada del claustro alto, catedral de Burgos. Foto: Rafael Cómez Ramos. 


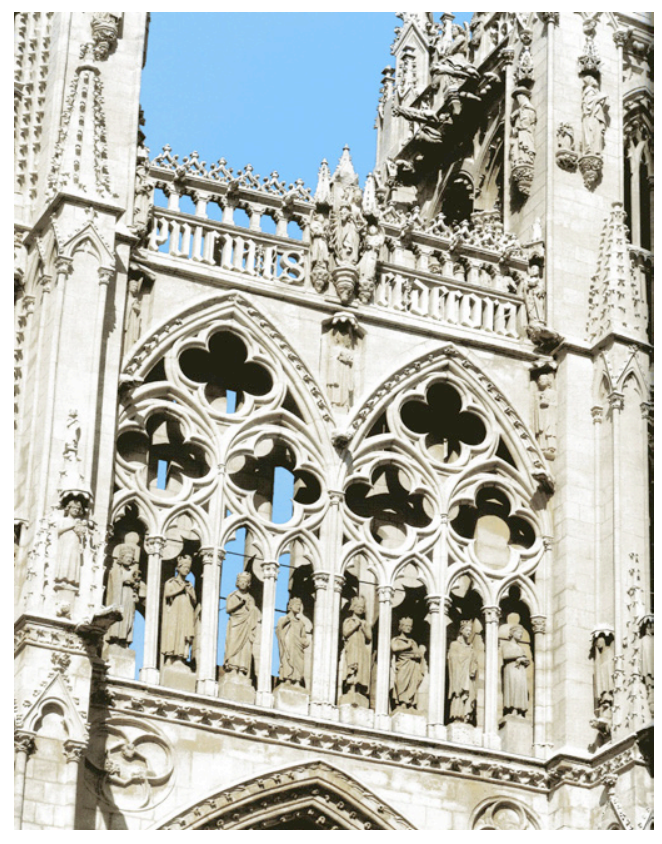

Figura 7. Galería alta de la fachada occidental, catedral de Burgos. Foto: Rafael Cómez Ramos.

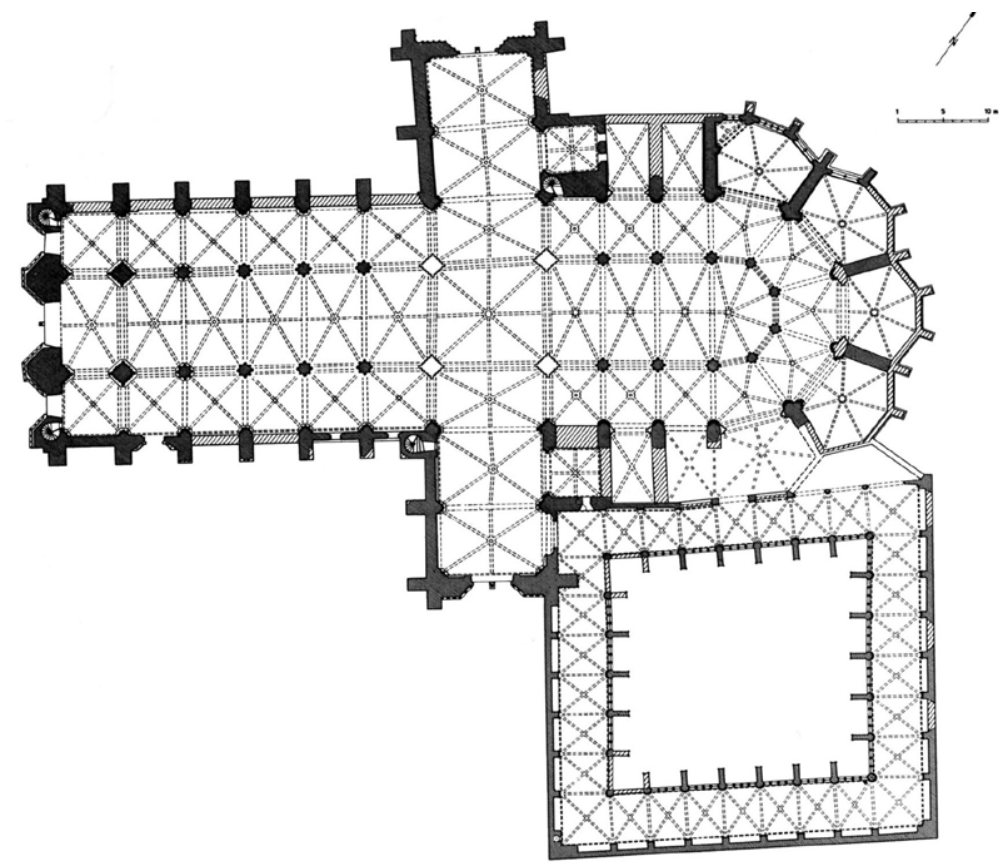

Figura 8. Planta, catedral de Burgos. KARGE, Henrik: La catedral de Burgos y la arquitectura del siglo XIII en Francia y España. Valladolid, 1995. 